\title{
La macroeconomía de la flotación sucia en una economía primario exportadora: el caso del Perú*
}

\author{
Waldo Mendoza Bellido*
}

\begin{abstract}
RESUMEN
El régimen de tipo de cambio en el Perú no es fijo ni flotante. El Banco Central de Reserva del Perú (BCRP) rema en contra de la corriente en el mercado cambiario. Tiende a comprar dólares cuando el tipo de cambio baja, y tiende a vender cuando el tipo de cambio sube. Es un esquema de flotación sucia.

En este artículo se presenta un modelo macroeconómico sencillo donde el banco central fija la tasa de interés y mantiene un régimen cambiario de flotación sucia, en el contexto de una economía pequeña, abierta, parcialmente dolarizada, exportadora de materias primas, con movilidad imperfecta de capitales y una política fiscal que opera con un límite al déficit fiscal estructural.

Las predicciones del modelo son consistentes con la regla de intervención del BCRP y los principales hechos estilizados de la economía peruana desde el inicio del descenso del precio internacional de las materias primas a fines de 2011: caída drástica de la inversión privada, descenso del crecimiento del PBI, alza del tipo de cambio nominal y reducción de las reservas internacionales.
\end{abstract}

Clasificación JEL: E52 y E58.

Palabras clave: Política monetaria, intervención cambiaria, flotación sucia, Banco Central de Reserva del Perú (BCRP).

\section{The Macroeconomics of Dirty Float In A Primary Export Economy: The Case of Peru}

\begin{abstract}
The current Peruvian exchange regime is neither pegged nor free-floating. The Peruvian Central Bank sails against the wind in the exchange market, tending to buy dollars when the exchange rate falls, and tending to sell when the exchange rate rises. It is a dirty float regime.
\end{abstract}

* Documento que forma parte del proyecto "Instrumentos y reglas de política monetaria en una economía semi-dolarizada: evaluación empírica del caso peruano", del grupo Macroeconomía Aplicada, con el apoyo financiero del Vicerrectorado de Investigación de la Pontificia Universidad Católica del Perú (PUCP).

** Profesor del Departamento de Economía de la PUCP. El autor agradece la asistencia de Érika Collantes. 
In this paper we present a simple macroeconomic model where the central bank fixes the interest rate and maintains a dirty floating exchange rate regime, assuming a small, open, and partiallydollarized economy that exports raw materials, faces imperfect capital mobility, and has a structural fiscal deficit limit as a rule for its fiscal policy.

The predictions of the model are consistent with the rule of foreign exchange intervention by the Central Bank and the main stylized facts of the Peruvian economy since the decline in the international price of raw materials in late 2011: drastic fall in private investment, decline of GDP growth, rising nominal exchange rate and reduction of international reserves.

JEL classification: E52 y E58.

Keywords: Monetary policy, exchange rate intervention, dirty float, Central Reserve Bank of Peru (BCRP).

\section{INTRODUCCIÓN}

El régimen de tipo de cambio en el Perú no es fijo ni flotante. Tal como se registra en el gráfico siguiente, el Banco Central de Reserva del Perú (BCRP) rema en contra de la corriente en el mercado cambiario. Tiende a comprar dólares cuando el tipo de cambio baja, y tiende a vender cuando el tipo de cambio sube. Es un esquema de flotación sucia.

Gráfico 1. Tipo de cambio y posición de cambio del BCRP

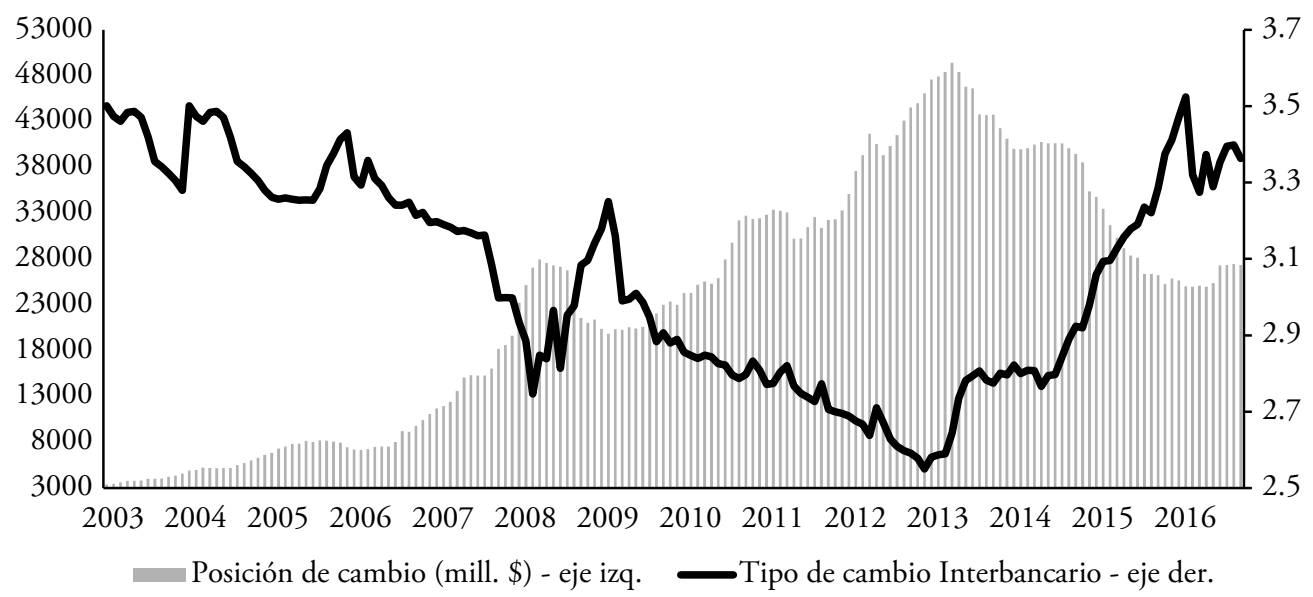

Fuente: BCRP

Desde el 2002, el régimen de flotación sucia es un brazo del esquema de política monetaria del banco central. Este esquema se lleva a la práctica en el Perú a través de dos instrumentos de política monetaria: la tasa de interés para mantener bajo control 
la inflación y la flotación sucia para limitar la volatilidad del tipo de cambio ${ }^{1}$. Este tipo de política ha sido avalada por Blanchard, Dell'Ariccia y Mauro (2010).

Por otro lado, hacia fines del 2011 se terminó el gran ciclo de auge del precio de las exportaciones que se inició en el 2003, tal como se puede ver en el gráfico 2.

Gráfico 2. Perú: Índice de precios de exportaciones (Ene 2003=100)

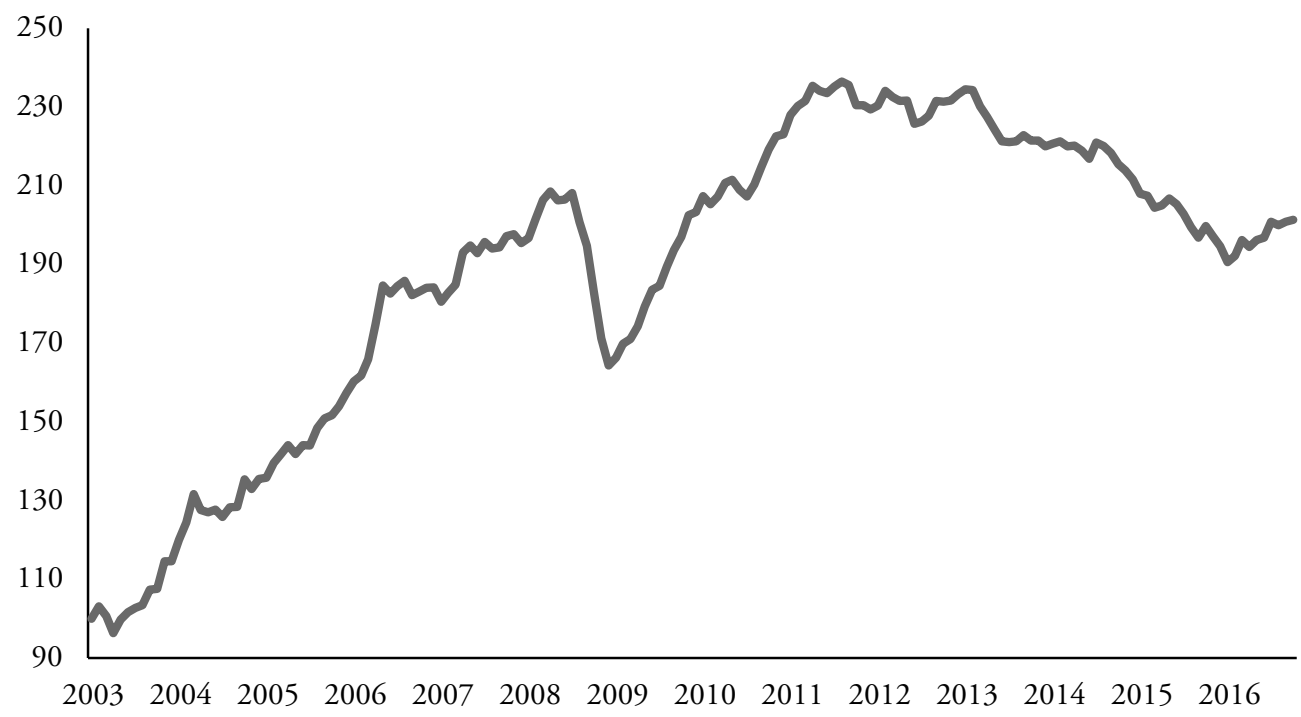

Fuente: BCRP

En el periodo 2003-2016 hay dos fases nítidamente distintas: el del 2003-2012, de notable elevación del precio de las exportaciones, y el 2013-2016, de fuerte caída. En la fase del auge 2003-2012, el precio de las exportaciones tradicionales, mayoritariamente mineras, se elevó en 15 por ciento anual, cayendo en 7 por ciento al año entre 2013 y 2016. En el auge, la inversión privada creció a 14 por ciento anual, y en el periodo 2013-2016 cayó a 1 por ciento al año. El PBI, en el auge, creció a 6.3 por ciento al año; en 2013-2116 en 3.8 por ciento. En el auge, el tipo de cambio nominal cayó en un 27 por ciento. Entre diciembre de 2012 y diciembre de 2016 se elevó en 40 por ciento. Por último, en el auge, las reservas internacionales del BCRP, la posición de cambio, subieron de US\$ 3402 millones a principios de 2003 a US\$ 46063 millones hacia fines de 2012. Con el descenso de los precios internacionales, la posición de cambio inició su camino descendiente, hasta llegar a US\$27 000 millones en diciembre de 2016.

\footnotetext{
1 Véase una descripción detallada de la política monetaria del BCRP en Rossini, Quispe y Rodríguez (2011).
} 
En resumen, los precios de las materias primas parecen haber tenido una influencia importante en el comportamiento de las principales variables de la macroeconomía peruana.

En este artículo se presenta un modelo macroeconómico donde el eje de atención es la flotación sucia, acompañado de un esquema de tasa de interés administrada, en el contexto de una economía pequeña, abierta, parcialmente dolarizada, exportadora de materias primas, con movilidad imperfecta de capitales y con una política fiscal que opera con un límite al déficit fiscal estructural. El modelo es de la familia de los modelos tipo Mundell-Fleming y tiene como objetivo contribuir a la literatura que agrupa modelos simples, que pueden ser útiles para la enseñanza de la macroeconomía a nivel de pre-grado, los cuales abstraen las expectativas de los agentes económicos y la dinámica de sus decisiones.

El modelo permite determinar los efectos de corto plazo de un descenso del precio internacional de las materias primas de exportación sobre la inversión privada, la producción, el tipo de cambio y las reservas de internacionales. No es habitual en los modelos macroeconómicos que tanto el tipo de cambio como el stock de reservas internacionales sean variables endógenas.

El modelo es consistente con la regla de intervención del BCRP y los principales hechos estilizados de la economía peruana desde el inicio del descenso del precio internacional de las materias primas a fines de 2011: caída drástica de la inversión privada, descenso del crecimiento del PBI, alza del tipo de cambio y reducción de las reservas internacionales.

El artículo está organizado de la siguiente manera. En la siguiente sección se presenta una discusión acerca de los regímenes cambiarios tradicionales, de tipo de cambio fijo o flotante, y el régimen de flotación sucia, en un mundo de movilidad imperfecta de capitales. En la sección 2 se presenta el modelo macroeconómico. En la sección 3 se utiliza el modelo para simular los efectos de un choque externo desfavorable, el descenso de los precios internacionales de las materias primas. Finalmente, la sección 4 es de conclusiones.

\section{MOVILIDAD IMPERFECTA DE CAPITALES Y REGÍMENES CAMBIARIOS}

Cuando la movilidad de capitales es imperfecta, es la ecuación de la balanza de pagos la que mejor representa el sector externo, y no la ecuación de paridad descubierta de tasas de interés con perfecta movilidad de capitales. Nuestro modelo supone movilidad imperfecta de capitales. La imperfección no deriva de la existencia de controles al libre movimiento de capitales sino a que los activos locales y los extranjeros son sustitutos imperfectos. 
La balanza de pagos comprende la balanza en cuenta corriente y la balanza de capitales. Dentro de la balanza en cuenta corriente abstraemos el resto de componentes y nos quedamos solo con la balanza comercial. Esta economía exporta bienes industriales y materias primas, importa bienes industriales, y no existen importaciones de materias primas. La balanza comercial de bienes industriales, o exportaciones netas de bienes industriales, como en los típicos modelos Mundell-Fleming, es una función directa del PBI internacional $\left(Y^{*}\right)$ y del tipo de cambio real $\left(E+P^{*}-P\right)^{2}$ y una función inversa del ingreso disponible, el ingreso neto de impuestos, $Y-T=(1-t) Y$, dada una propensión marginal a importar $(m)$. Las exportaciones de materias primas, expresadas en términos de bienes industriales, vienen representadas por $\left(E+P_{X}^{*}-P\right) X_{0}{ }^{3}$.

En las expresiones anteriores, $Y$ es el PBI industrial, $t$ la tasa impositiva $(T=t Y), E$ el tipo de cambio nominal, $P$ el nivel de precios industriales, $P^{*}$ el precio internacional de los bienes industriales, $P_{X}^{*}$ el precio internacional de las exportaciones de materias primas y $X_{0}$ el volumen de exportaciones de materias primas, considerado exógeno, porque este sector produce a plena capacidad.

Respecto a la balanza de capitales, limitamos la atención a los ingresos netos de capitales financieros, los cuales son una función directa del diferencial existente entre la tasa de interés local $(r)$ y la tasa de interés internacional $\left(r^{*}\right)$, ajustada por la tasa de depreciación esperada $\left(E^{e}-E\right)^{4}$.

La ecuación de la balanza de pagos viene entonces dada por,

$$
\begin{aligned}
& B^{*} b c r- B_{t-1}^{* b c r}= \\
& a_{2}\left(r-r^{*}-E^{e}+E\right)
\end{aligned}
$$

Aquí, $B^{* b c r}-B_{t-1}^{* b c r}$ es el resultado de la balanza de pagos, que equivale a la variación entre un periodo y otro de las reservas internacionales, siendo $B^{*}$ bcr el stock de reservas internacionales del banco central del periodo actual y $B_{t-1}^{* b c r}$ el stock del periodo previo. En el plano del tipo de cambio nominal y las reservas internacionales, la balanza de pagos queda representada con la ecuación (2) y la figura 1 .

$$
\begin{aligned}
E=\left[\frac{m(1-t) Y-a_{1} P^{*}-P_{X}^{*} X_{0}+\left(a_{1}+X_{0}\right) P-a_{0} Y^{*}+a_{2}\left(r^{*}+E^{e}-r\right)-B_{t-1}^{* b c r}}{a_{1}+a_{2}+X_{0}}\right] & \\
& +\frac{B^{*} b c r}{a_{1}+a_{2}+X_{0}}
\end{aligned}
$$

2 En todo el artículo, trabajaremos con presentaciones lineales de algunas variables. Los modelos lineales tienen la gran ventaja de su sencillez. Por ejemplo, en este caso, estamos utilizando la presentación lineal para el tipo de cambio real $E+P^{*}-P$.

3 Aquí estamos apelando a la presentación lineal del precio real de las exportaciones de materias primas $E+P_{X}^{*}-P$.

4 También aquí, para mantener el carácter lineal del modelo, la tasa de depreciación esperada es aproximada por $E^{e}-E . E^{e}$ es el tipo de cambio esperado, considerado exógeno. 
Figura 1. La balanza de pagos

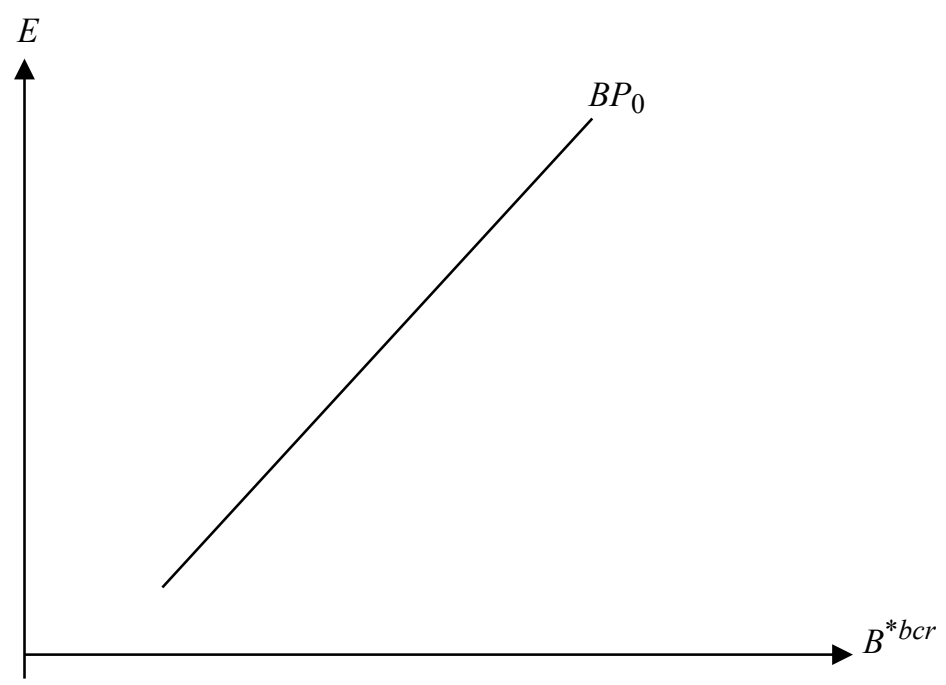

\section{LOS ESQUEMAS DE TIPO DE CAMBIO FIJO Y TIPO DE CAMBIO FLOTANTE}

La ecuación (1) es muy útil para discutir los esquemas de tipo de cambio fijo y de tipo de cambio flotante, en un mundo de movilidad imperfecta de capitales.

En el régimen de tipo de cambio fijo, el banco central define el tipo de cambio, con lo cual etipo de cambio es exógeno $\left(E=E_{0}\right)$ y el volumen de reservas internacionales es endógeno, pues el banco tiene que intervenir en el mercado cambiario, comprando o vendiendo dólares, para hacer que el tipo de cambio de mercado sea igual al fijado por la autoridad monetaria. En consecuencia, la ecuación de determinación de las reservas internacionales viene dada por,

$$
\begin{aligned}
B^{* b c r}= & B_{t-1}^{* b c r}+a_{0} Y^{*}+a_{1}\left(E_{0}+P^{*}-P\right)-m(1-t) Y+\left(E_{0}+P_{X}^{*}-P\right) X_{0} \\
& +a_{2}\left(r-r^{*}-E^{e}+E_{0}\right)
\end{aligned}
$$

En el régimen de tipo de cambio flexible, el tipo de cambio es endógeno y el banco central no interviene en el mercado cambiario, por lo que el volumen de reservas internacionales es una variable exógena que permanece constante $\left(B^{* b c r}-B_{t-1}^{* b c r}=0\right)^{5}$. La ecuación de determinación del tipo de cambio viene dada por,

$$
E=\left[\frac{m(1-t) Y-a_{1} P^{*}-P_{X}^{*} X_{0}+\left(a_{1}+X_{0}\right) P-a_{0} Y^{*}+a_{2}\left(r^{*}+E^{e}-r\right)}{a_{1}+a_{2}+X_{0}}\right]
$$

\footnotetext{
5 Otra posibilidad es que se considere que es el volumen de compras (o ventas) de dólares del banco central lo que se considera exógeno, de tal forma que $B^{* b c r}-B_{t-1}^{* b c r}=z$, donde $z$ es una constante.
} 
Entre estos dos regímenes extremos, hay uno intermedio, el de la flotación sucia, que es el que nos interesa estudiar.

\section{a. Flotación sucia e intervención cambiaria}

El banco central de este modelo no tiene un tipo de cambio fijo, pero tampoco uno flotante, en los términos presentados en la sección anterior. Tiene un sistema cambiario híbrido, con una flexibilidad limitada del tipo de cambio, debido a la intervención cambiaria que funciona con alguna noción de cuál es un tipo de cambio "adecuado". Varios trabajos, como el de Adler, Lisack y Mano (2015), han mostrado la efectividad de dicha intervención: la intervención cambiaria esterilizada altera el nivel del tipo de cambio nominal.

En este régimen híbrido, de flotación sucia, el banco central tiene una regla de intervención que rema contra la corriente. El banco tiende a comprar dólares cuando su precio baja con relación a un tipo de cambio meta $\left(E^{m}\right)$, implícito, no anunciado; y tiende a vender cuando su precio sube por encima de ese tipo de cambio meta. Una regla de intervención simple (Dancourt 2013, FMI 2014) que reproduce bien este régimen de flotación sucia es la siguiente.

$$
B^{* b c r}=B_{t-1}^{* b c r}+\beta_{0}\left(E^{m}-E\right)
$$

En esta regla, cuando el tipo de cambio de mercado se ubica por debajo del tipo de cambio meta, $E<E^{m}$ (por encima del tipo de cambio meta, $E>E^{m}$ ), el banco central compra dólares, $B^{* b c r}-B_{t-1}^{* b c r}>0$ (el banco central vende dólares, $B^{* b c r}-B_{t-1}^{* b c r}<0$ ), procurando elevar (bajar) el precio de la moneda extranjera. Cuando el tipo de cambio de mercado iguala al tipo de cambio meta $E=E^{m}$, de acuerdo a la ecuación (5), el banco central no interviene, $B^{* b c r}-B_{t-1}^{* b c r}=0$. O, lo que es lo mismo, el tipo de cambio meta es aquel que resulta de la flotación limpia del tipo de cambio ${ }^{6}$. Con esta regla de intervención, el banco central evita las apreciaciones y las depreciaciones excesivas de la moneda nacional respecto a su valor meta.

Es evidente que en la práctica real de la política monetaria, no puede considerarse al tipo de cambio meta como una constante. Esta variable debe moverse a lo largo del tiempo en función a la evolución de los determinantes fundamentales del tipo de cambio. La endogenización del tipo de cambio meta, sin embargo, excede a las pretensiones de este artículo.

La ecuación (5) es, en realidad, una expresión general que comprende a todos los regímenes cambiarios en un mundo de movilidad imperfecta de capitales, puesto que $\beta_{0}$

\footnotetext{
6 Este tipo de cambio meta puede entonces encontrarse estadísticamente, identificando los periodos en los cuales el banco central no interviene (o interviene muy poco) en el mercado cambiario. El tipo de cambio vigente en esos periodos sería el tipo de cambio meta.
} 
es el grado de sensibilidad de la intervención cambiaria, $B^{* b c r}-B_{t-1}^{* b c r}$, respecto al diferencial entre el tipo de cambio meta y el tipo de cambio observado $\left(E^{m}-E\right)$. Cuando ese grado de sensibilidad es nulo $\left(\beta_{0}=0\right)$, entonces, en (5), estamos en el mundo del tipo de cambio flexible, donde el banco central no interviene en el mercado de dólares, cualquiera sea el diferencial entre el tipo de cambio de mercado y el tipo de cambio meta, y por tanto las reservas internacionales permanecen constantes. En realidad, dentro de un tipo de cambio flotante, no hay un tipo de cambio meta, fijo, pues el tipo de cambio observado es siempre el tipo de cambio apropiado, o tipo de cambio meta.

$$
B^{* b c r}=B_{t-1}^{* b c r}
$$

En el otro caso extremo, cuando dicha sensibilidad tiende a infinito $\left(\beta_{0} \rightarrow \infty\right)$, el banco central interviene ante la aparición del menor indicio de discrepancia entre el tipo de cambio meta y el tipo de cambio observado, por lo que estamos en el mundo del tipo de cambio fijo. El banco central fija el tipo de cambio en el nivel que considera es su meta.

$$
E^{m}-E
$$

La regla de intervención de la ecuación (5) puede ser graficada en el plano del tipo de cambio y las reservas internacionales. A esta recta de intervención cambiaria la denominaremos RI. Es la ecuación (6) y se la representa en la figura 2.

$$
E=E^{m}+\frac{B_{t-1}^{* b c r}}{\beta_{0}}-\frac{B^{* b c r}}{\beta_{0}}
$$

Figura 2. La regla de intervención

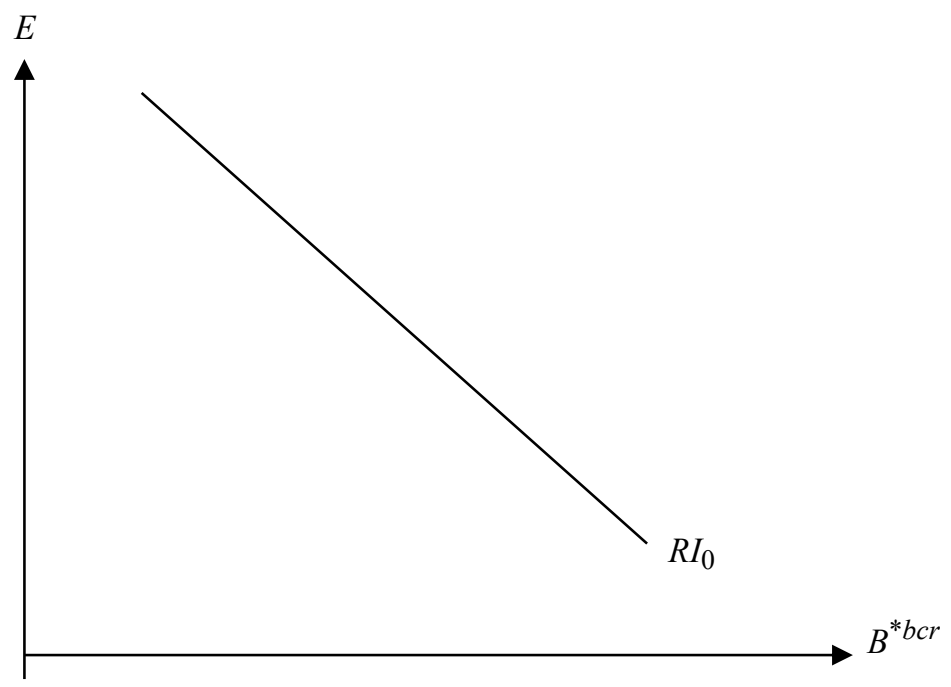


En la figura 3, dada la ecuación de balanza de pagos (BP), que es común para los tres regímenes cambiarios, el régimen de tipo de cambio flotante se expresa en la ecuación (5.1) y la recta FL; el régimen de tipo de cambio fijo viene dada por la ecuación (5.2) y la recta FI; y el régimen de flotación sucia es la ecuación (6) y la recta RI.

Figura 3. Flotación limpia, flotación sucia y tipo de cambio fijo

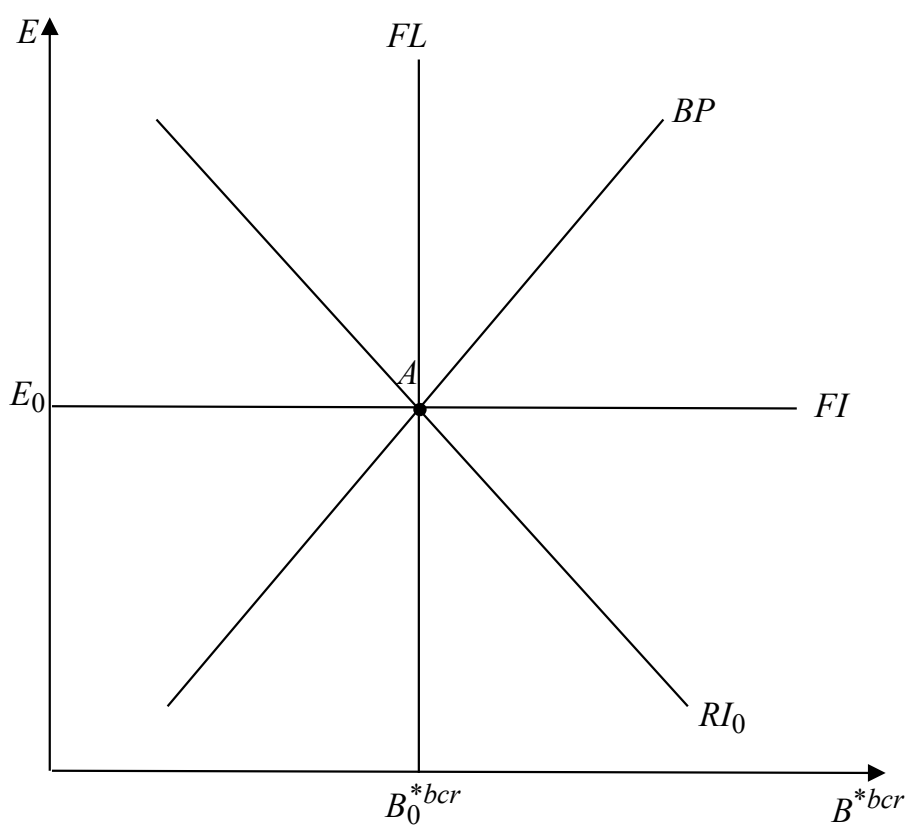

El régimen de flotación sucia es entonces un régimen intermedio entre el fijo, donde el stock de reservas internacionales es una variable endógena, y el flexible, donde la variable endógena es el tipo de cambio. En este régimen intermedio, donde se impide que el tipo de cambio fluctúe demasiado, tanto el stock de reservas como el tipo de cambio son variables endógenas. Es el régimen que consideraremos en la presentación del modelo macroeconómico en la sección siguiente. No es usual encontrar modelos donde tanto el tipo de cambio como las reservas internacionales sean variables endógenas

Conjugando las ecuaciones (1) y (5), de balanza de pagos y de intervención cambiaria, arribamos a las ecuaciones (7) y (8), que son las ecuaciones de determinación de las reservas internacionales y el tipo de cambio, respectivamente.

$$
\begin{aligned}
B^{* b c r}= & B_{t-1}^{* b c r}+\beta_{0}\left(\frac{\mu-\beta_{0}}{\mu}\right) E^{m} \\
& -\frac{\beta_{0}}{\mu}\left[-a_{0} Y^{*}-a_{1} P^{*}-P_{x}^{*} X_{0}+a_{2}\left(r^{*}+E^{e}-r\right)+\left(a_{1}+X_{0}\right) P+m(1-t) Y\right]
\end{aligned}
$$




$$
E=\frac{1}{\mu}\left[\beta_{0} E^{m}-a_{0} Y^{*}+\left(a_{1}+X_{0}\right) P-a_{1} P^{*}-P_{X}^{*} X_{0}+a_{2}\left(r^{*}+E^{e}-r\right)\right]+\frac{m(1-t) Y}{\mu}
$$

Donde $\mu=a_{1}+a_{2}+\beta_{0}+X_{o}$

Estamos ahora en condiciones de discutir cómo se comportan los tres regímenes cambiarios ante un choque externo común, para entender la lógica del esquema de flotación sucia.

\section{b. Flotación sucia, flotación limpia y tipo de cambio fijo}

¿Cómo funciona un régimen de tipo de cambio fijo, uno flotante y otro con flotación sucia? Una manera práctica de contestar esta pregunta es evaluando cómo reaccionan estos distintos regímenes cambiarios frente a un choque externo adverso, por ejemplo, el proveniente de un descenso del precio internacional de las materias primas.

Con tipo de cambio fijo, el descenso del precio de las materias primas reduce el valor de las exportaciones, empeora la balanza comercial y produce un déficit de balanza de pagos, que genera presiones al alza en el tipo de cambio. Como el banco central quiere mantener fijo el tipo de cambio, debe vender dólares, y así financiar el déficit de balanza de pagos, reduciendo su tenencia de reservas internacionales. Es lo que se observa en la ecuación (3). El tipo de cambio se mantiene fijo, pero se caen las reservas internacionales del banco central.

En un régimen de tipo de cambio flotante, ante el mismo choque externo, el banco central no interviene en el mercado cambiario, mantiene su volumen de reservas internacionales intacto y permite que el tipo de cambio se eleve para mantener equilibrada la balanza de pagos. El mayor tipo de cambio mejora la balanza comercial de bienes industriales, atrae más capitales de corto plazo, atenúa la caída del precio real de las exportaciones de materias primas y de esa manera se reestablece el equilibrio de la balanza de pagos. Es lo que se aprecia en la ecuación (4). Las reservas internacionales se mantienen fijas, a costa del alza en el tipo de cambio.

Finalmente, en el régimen de flotación sucia, ante la caída del precio mundial de las exportaciones de materias primas, el banco central permite el alza, pero moderada, del tipo de cambio, pues interviene en el mercado cambiario, al costo de perder reservas internacionales. El alza en el tipo de cambio y la reducción en las reservas internacionales se aprecian en las ecuaciones (7) y (8), respectivamente.

Puede demostrase, a partir de las ecuaciones (3), (4), (7) y (8), que la pérdida de reservas internacionales en el régimen de flotación sucia es menor que en el régimen de tipo de cambio fijo, y que el alza del tipo de cambio es menor que en el de flotación limpia. 
En la figura 4 se aprecian los distintos mecanismo de ajuste ante el choque externo. En la figura se presentan la recta de balanza de pagos BP, la regla de intervención RI, la recta horizontal FI que representa el régimen de tipo de cambio fijo y la recta vertical FL que representa el régimen de tipo de cambio flotante. El equilibrio inicial se da en el punto A.

Ante un descenso del precio internacional de las materias primas, la recta BP se desplaza hacia la izquierda. Con tipo de cambio fijo el equilibrio se traslada al punto B, con el mismo tipo de cambio y menores reservas internacionales. Con tipo de cambio flotante el equilibrio se mueve al punto $\mathrm{C}$, con un mayor tipo de cambio y el mismo volumen de reservas internacionales. Con la flotación sucia, el equilibrio se desplaza al punto $\mathrm{D}$, con un mayor tipo de cambio (menor al del tipo de cambio flexible) y menores reservas internacionales (mayores al del tipo de cambio fijo).

Figura 4. Choque externo adverso y regímenes cambiarios

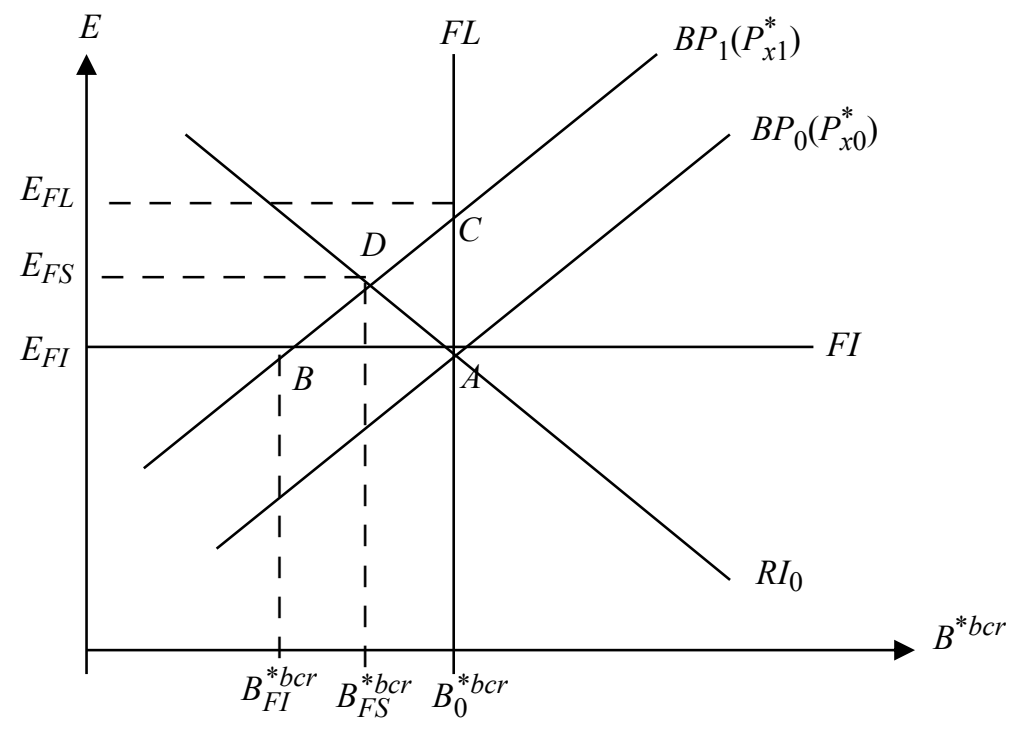

El régimen de flotación sucia es entonces un régimen intermedio entre el fijo y el flotante, que impide fluctuaciones exageradas del tipo de cambio y las reservas internacionales.

Explicado el régimen de flotación sucia en equilibrio parcial, pasamos ahora a entender su funcionamiento en el equilibrio general, en el que se establecen las interacciones entre la regla de intervención, el mercado de bienes, la balanza de pagos y el mercado monetario. 


\section{EL MODELO MACROECONÓMICO7}

Este modelo reproduce dos rasgos importantes.

En primer lugar, esta economía es pequeña, abierta, parcialmente dolarizada, primario exportadora, dependiente del financiamiento externo y donde la movilidad de capitales es imperfecta, en el sentido de que los activos locales y externos no son sustitutos perfectos.

En segundo lugar, reproduce un régimen particular de políticas macroeconómicas. En el terreno de la política monetaria, en un mundo de movilidad imperfecta de capitales, el banco central trabaja con un esquema monetario con dos instrumentos, la tasa de interés de corto plazo para controlar la inflación y la intervención cambiaria, la flotación sucia, para evitar la extrema volatilidad del tipo de cambio ${ }^{8}$. En el campo de la política fiscal, la autoridad correspondiente se guía por una regla que impone límites al déficit fiscal estructural'.

En el modelo, el carácter primario exportador replica el clásico trabajo de Díaz Alejandro (1966), formalizado por Krugman y Taylor (1978) y adaptado por Dancourt (2013) para el caso peruano. La movilidad imperfecta de capitales es una variedad de los modelos del tipo Mundell-Fleming, como el de Ball (2012) o el de Ostry, Ghosh y Chamon (2012).

El mercado de bienes lo conforman dos sectores productivos. Existe un sector productor de bienes industriales, keynesiano, donde la producción se ajusta a la demanda, parte de la cual se origina en el sector exportador de materias primas. Este otro sector opera a pleno empleo y produce solo para la exportación. El gasto público es endógeno, pues existe una regla de política que impone un límite al déficit fiscal estructural como porcentaje del PBI potencial.

Combinando el equilibrio en el mercado de bienes, el mercado monetario, la balanza de pagos y la regla de intervención, arribamos a la demanda agregada de esta economía.

En este modelo de corto plazo, en el lado de la oferta agregada, suponemos que el nivel de precios es exógeno. No es objetivo de este artículo explicar los determinantes del nivel de precios. Para un modelo de este tipo, donde el nivel de precios es una función del tipo de cambio y la brecha del producto, véase Dancourt y Mendoza (2016).

\footnotetext{
7 El modelo presentado aquí es una variante del de Dancourt y Mendoza (2016). Se diferencia en varios aspectos. En primer lugar, en temas de forma, a pesar de que los aspectos tratados son poco convencionales, se busca una presentación más estándar, cercana a la de los libros de texto más comunes de Macroeconomía, El propósito es facilitar la lectura de este trabajo. En segundo lugar, en aspectos de fondo, se hace un tratamiento más comprensivo de los esquemas cambiarios, se considera una regla de déficit fiscal estructural , y se concentra la atención en la forma cómo impacta un descenso del precio de las exportaciones de materias primas en una economía con los rasgos estructurales de la economía peruana. Véase, también, Mendoza (2015). 8 Un modelo donde la política monetaria tiene también dos objetivos y dos instrumentos, como el presentado en este artículo, es el de Ostry, Ghosh y Chamon (2012).

9 En el caso peruano, regido por la Ley de Fortalecimiento de la Responsabilidad y Transparencia Fiscal (LFRTF), Ley 30099 y sus modificatorias.
} 


\section{LA DEMANDA AGREGADA}

\section{a. El mercado de bienes}

Esta economía tiene dos sectores productivos, similares a los de Díaz Alejandro (1966). Hay un sector que produce materias primas solo para la exportación, que opera a plena capacidad, y un sector industrial, keynesiano, que opera con capacidad ociosa, que produce para el mercado local, para la exportación y compite con importaciones de bienes sustitutos. Por el carácter de economía pequeña, los precios internacionales de las materias primas y de los bienes industriales son exógenos.

La conexión entre ambos sectores puede ser diversa. En Díaz Alejandro (1966), y Krugman y Taylor (1978), los trabajadores y empresarios del sector de materias primas consumen bienes industriales. Un alza del precio de las materias primas reactiva la industria porque eleva el consumo proveniente de los trabajadores y empresarios del sector de materias primas. Sin embargo, este tipo de conexión puede ser débil, en la medida que el sector de materias primas no es intensivo en mano de obra y que la mayor parte de los beneficios son repatriados al exterior, pues casi todas las inversiones en este sector son de no residentes ${ }^{10}$.

En este artículo, la conexión entre ambos sectores se produce a través de otros canales. Por un lado, el gobierno recauda el impuesto a la renta procedente del sector de materias primas y lo gasta en la industria. Por otro lado, el precio de las materias primas de exportación es un determinante importante de la demanda de inversiones en la industria.

En el sector de bienes industriales, el mecanismo de ajuste es keynesiano. La producción $(Y)$ se ajusta a la demanda $(D)$, la cual depende del consumo $(C)$, la inversión privada $(I)$, el gasto público $(G)$ y las exportaciones netas de bienes industriales $(X N)$.

$$
Y=D=C+I+G+X N
$$

El consumo, en presencia de restricciones de liquidez en el sistema financiero, está asociado al ingreso disponible. El ingreso disponible $\left(Y_{d}\right)$ es la diferencia entre el ingreso o producto $(Y)$ y los impuestos $(T)$, y estos son una proporción del nivel de actividad económica industrial $(T=t Y)$. Se considera solo un tipo de impuestos, el impuesto a la renta, que grava con la misma tasa $t$ tanto a los salarios como a las utilidades.

De esta manera, el ingreso disponible se define como $Y_{d}=Y-T=(1-t) Y$, y el consumo privado está representado en la ecuación (10).

$$
C=C_{0}+c(1-t) Y
$$

\footnotetext{
10 Por eso, en el modelo, no se considera en el consumo de bienes industriales la parte proveniente de los trabajadores y empresarios del sector productor de materias primas. Dancourt y Mendoza (2016) sí lo consideran.
} 
La inversión privada depende inversamente de la tasa de interés local $(r)$ y de la tasa de interés internacional $\left(r^{*}\right)$, y directamente del precio internacional de las exportaciones de materias primas, expresado en términos de bienes nacionales, $\left(E+P_{X}^{*}-P\right)$. La presencia de dos tasas de interés refleja el hecho de que las firmas locales pueden financiar sus inversiones en el mercado local, en moneda local, o en el mercado extranjero, en moneda extranjera. Puede reflejar también la dolarización parcial de los créditos bancarios de una economía.

La presencia del precio internacional de las materias primas reproduce el hecho estilizado encontrado por Magud y Sosa (2015), de una correlación positiva entre la inversión privada y el precio internacional de las exportaciones de materias primas en América Latina y el Caribe. La idea es que el sector de materias primas, como el minero, crea demanda para el sector industrial, como el de construcción. En FMI (2015, capítulo 2) se presenta un respaldo empírico contundente a la relación positiva existente entre la inversión privada de las grandes compañías productoras de metales en el mundo y los precios reales de los metales. Por último, Ross y Tashu (2015) encuentran que el precio de las exportaciones de materias primas es uno de los determinantes más importante de la inversión privada en el Perú.

Sobre la base de las consideraciones anteriores, se postula una ecuación para la inversión privada como la siguiente,

$$
I=I_{0}-b r-b^{*} r^{*}+b^{x}\left(E+P_{X}^{*}-P\right)
$$

Por otro lado, en el ámbito fiscal, modelaremos el caso en el que existe una meta de déficit fiscal estructural como porcentaje del PBI potencial $(\alpha)^{11}$.

El déficit fiscal estructural $(D F E)$ es la diferencia entre los gastos y los ingresos estructurales totales del sector público. Los gastos y los ingresos están valuados en términos de bienes industriales, y se asume que los gastos son independientes del ciclo económico. Los gastos comprenden los no financieros o primarios (sueldos, gasto en infraestructura física, gasto en bienes y servicios), $G$, y los financieros. Estos últimos corresponden a los intereses de la deuda pública en moneda nacional, esto es, a la tasa de interés en moneda nacional multiplicada por el stock de deuda pública en dicha moneda, $r B^{g}$, y los intereses de la deuda pública en moneda extranjera, es decir, el tipo de cambio real, $E-P$, multiplicado por la tasa de interés internacional $r^{*}$ y el stock de deuda pública externa $B^{* g},(E-P) r^{*} B^{* g}{ }^{12}$.

Los ingresos estructurales provienen del impuesto a la renta aplicado en la industria, $t \bar{Y}$, y en el sector de materias primas de exportación, $t\left(E+\overline{P_{X}^{*}}-P\right) X_{0}$, donde $X_{0}$ es el volumen de exportaciones de materias primas, $\bar{Y}$ es el PBI industrial potencial

11 En enero de 2017 el Ministerio de Economía y Finanzas ha modificado esta ley, abandonando la regla del déficit estructural. Este cambio no afecta las predicciones esenciales de este modelo.

12 Es la versión lineal de los interese de la deuda pública en términos reales, $\frac{\operatorname{Er}^{*} B^{*} g}{. P}$. 
o de pleno empleo y $\overline{P_{X}^{*}}$ representa la tendencia de largo plazo del precio mundial de las materias primas. La tasa $t$ del impuesto a la renta grava por igual a los trabajadores y a los empresarios de los dos sectores productivos de esta economía.

Como el déficit fiscal estructural tiene como límite ${ }^{13}$ un porcentaje $\alpha$ de la producción industrial potencial, la ecuación correspondiente viene dada $\operatorname{por}^{14}$,

$$
D F E=G+r B^{g}+(E-P) r^{*} B^{* g}-t \bar{Y}-t\left(E+\overline{P_{X}^{*}}-P\right) X_{0}=\alpha \bar{Y} .
$$

En consecuencia, el gasto público primario es endógeno y es una función directa de la tasa impositiva, el límite de déficit fiscal, el nivel de actividad económica industrial potencial, el precio tendencial de las materias primas, y una función inversa del pago de intereses de la deuda pública en moneda nacional y en moneda extranjera. En aras de la sencillez, suponemos que los volúmenes de deuda pública en moneda nacional y en moneda extranjera están dados. También aquí estamos utilizando las aproximaciones lineales para el tipo de cambio real $\left(\frac{E}{P} \cong E-P\right)$ y el precio real de las exportaciones de materias primas $\left(\frac{E P_{X}^{*}}{P} \cong E+P_{X}^{*}-P\right)$.

$$
G=(t+\alpha) \bar{Y}+t\left(E+\overline{P_{X}^{*}}-P\right) X_{0}-r B^{g}-(E-P) r^{*} B^{* g}
$$

Por último, las exportaciones netas, o balanza comercial de bienes industriales, dependen directamente del PBI internacional $Y^{*}$, por su influencia en el volumen de las exportaciones industriales, y del tipo de cambio real $\left(E+P^{*}-P\right)^{15}$, que refleja la competitividad de la economía; e inversamente del ingreso disponible, por su efecto sobre las importaciones, dada una propensión marginal a importar $(m)$.

$$
X N=a_{0} Y^{*}+a_{1}\left(E+P^{*}-P\right)-m(1-t) Y
$$

13 En rigor, El DFE es menor o igual que el límite dado por la Ley. Por sencillez asumimos que el DFE es igual a dicho límite.

${ }_{14} \mathrm{La}$ definición precisa del déficit fiscal estructural en términos de bienes industriales viene dada por $D F E=G+r\left(B^{g}-P\right)+(E-P) r^{*} B^{* g}-t \bar{Y}-t\left(E+\bar{P}_{X}^{*}-P\right) X_{0}=\alpha \bar{Y}$. En esta ecuación puede apreciarse que un alza en el nivel de precios, además de sus otros efectos, «licúa» el saldo de la deuda pública interna en términos reales $\left(B^{g}-P\right)$. La simplificación en la medición de los intereses de la deuda pública en moneda local es necesaria para preservar el carácter lineal del modelo. De esta simplificación se desprende una curva de demanda agregada lineal: ganaremos en sencillez y perderemos algo en rigurosidad.

${ }^{15}$ El tipo de cambio real que explica el comportamiento de las exportaciones netas incluye, como corresponde, el precio internacional de los bienes industriales $\left(\frac{E P^{*}}{P} \cong E+P^{*}-P\right)$, mientras que el que determina el gasto público no financiero es el tipo de cambio real que solo toma en cuenta el precio interno $(E-P)$. 
Reemplazando los valores del consumo, la inversión privada, el gasto público y las exportaciones netas en la ecuación (9), el equilibrio en el mercado de bienes industriales viene dado por,

$$
Y=k\left[A_{0}+b^{X} P_{X}^{*}-\left(b+B^{g}\right) r-b^{*} r^{*}+a_{e}(E-P)\right]
$$

Donde $k=\frac{1}{1-(1-t)(c-m)}$ es el multiplicador keynesiano, cuyo valor es mayor que la unidad. Además, $A_{0}=C_{0}+I_{0}+(t+\alpha) \bar{Y}+t \overline{P_{X}^{*}} X_{0}+a_{0} Y^{*}+a_{1} P^{*}$ es el componente autónomo de la demanda agregada. Por último, $a_{e}=b^{x}+t X_{0}+a_{1}-r^{*} B^{* g}$, es el efecto del tipo de cambio real, $(E-P)$, sobre la demanda por bienes industriales.

El carácter recesivo o expansivo de la elevación del tipo de cambio real depende de este último componente, $a_{e}$. El elemento $b^{x}$ es el impacto positivo que tiene el alza del tipo de cambio real sobre la inversión privada, por su efecto en el precio real de las exportaciones de materias primas, al que denominaremos el efecto inversión. El componente $t X_{0}$ es el impacto positivo que tiene el alza del tipo de cambio real en el gasto público, por su efecto en los impuestos provenientes de la exportación de materias primas, al que llamaremos el efecto recaudación. El parámetro $a_{1}$ es el efecto competitividad, y representa el efecto positivo de una elevación del tipo de cambio real sobre la balanza comercial -el conocido efecto Marshall-Lerner- Por último, el componente $-r^{*} B^{* g}$ registra el efecto hoja de balance del sector público, que muestra que cuando sube el tipo de cambio real, aumenta el pago de intereses de la deuda pública externa y, por tanto, disminuye el gasto primario del sector público y la demanda del bien industrial.

En consecuencia, el alza del tipo de cambio real puede tener consecuencias expansivas o recesivas sobre la producción industrial dependiendo de si la suma de los efectos inversión, recaudación y competitividad, $b^{x}+t X_{0}+a_{1}$, es mayor o menor que el efecto hoja de balance, $-r^{*} B^{* g}{ }^{16}$. ¿Un alza del tipo de cambio real eleva o hace caer el nivel de actividad económica?

Las evidencias para América Latina no son concluyentes. En el trabajo de Galindo, Izquierdo y Montero (2007), realizado con un panel de 9 países de América Latina ${ }^{17}$, con información para distintos años de la década del noventa, se encuentra, como cabe esperar, un efecto competitividad positivo y un efecto hoja de balance negativo, mientras que el efecto total no es preciso, pues depende del grado de dolarización de las economías. En las muy dolarizadas prevalece el efecto hoja de balance y en las menos dolarizadas el efecto competitividad.

${ }^{16}$ Estamos circunscribiendo el efecto hoja de balance al sector público. Podríamos extenderlo al sector privado, considerando la dolarización parcial del sistema bancario, sin alterar las conclusiones fundamentales de este modelo.

17 Argentina, Brasil, Bolivia, Chile, Colombia, Costa Rica, Perú, México y Uruguay. 
Para el caso peruano, Han (2014) modela el caso de una economía pequeńa y parcialmente dolarizada, y encuentra que un alza del tipo de cambio real recesa la actividad económica, aunque la vinculación no es estadísticamente significativa.

En estas condiciones, no es del todo arbitrario asumir en el modelo que el efecto total del tipo de cambio real sobre el nivel de actividad económica, en el corto plazo, es nulo. Es decir, los efectos inversión, recaudación y competitividad se compensan con el efecto hoja de balance.

Esa asunción no implica que $a_{e}=0$ en la ecuación (14). En dicha ecuación, si se calcula la derivada parcial de la producción con respecto al tipo de cambio real y con respecto a $a_{e}$, llegamos a la siguiente expresión, $d Y=k a_{e 0} d(E-P)+k(E-P)_{0} d a_{e}$.

Donde $a_{e 0}$ es la derivada parcial de la producción con respecto al tipo de cambio real, en la situación inicial o punto de partida del ejercicio de estática comparativa y $(E-P)_{0}$ es el tipo de cambio real inicial o de punto de partida. En términos matemáticos, estos son parámetros iniciales de los ejercicios de estática comparativa, por lo que permanecen constantes en dichos ejercicios.

El supuesto de que el tipo de cambio real no afecta a la producción, en el corto plazo, implica que $a_{e 0}=0$, por lo que, en la expresión anterior, $k a_{e 0} d(E-P)=0$. Es decir, un movimiento del tipo de cambio real, dado $a_{e 0}$, que es igual a cero, no afecta a la producción. Pero, dado el tipo de cambio real en la situación inicial, $(E-P)_{0}$, una modificación de algún componente de $a_{e}$, como $r^{*}, P_{x}^{*}, t$ o $X_{0}$, si afecta a la producción. Por ello se cumple que $k(E-P)_{0} d a_{e} \neq 0$.

Es por esta razón que mantenemos el componente $a_{e}$ en las ecuaciones, pero procederemos como lo acabamos de explicar cuando desarrollemos los ejercicios de estática comparativa ${ }^{18}$.

Aclarada la relación entre el tipo de cambio real y la producción industrial, denominamos IS a la ecuación (14), expresada en el plano $(Y, E)$, la que contiene las distintas combinaciones de tipo de cambio y producción que mantienen en equilibrio el mercado de bienes industriales ${ }^{19}$. Esta recta, dado que el tipo de cambio real no afecta al nivel de actividad económica, es completamente vertical.

${ }^{18}$ El modelo es lo suficientemente flexible como para trabajar con el caso de la devaluación expansiva $\left(a_{e}>0\right)$ o el de la devaluación contractiva $\left(a_{e}<0\right)$. La opción elegida aquí es la más sencilla pues no considera los efectos del tipo de cambio real sobre la producción industrial, por lo que el tipo de cambio nominal y el nivel de precios no son parámetros de la IS. El caso de la devaluación expansiva es un poco más complejo, porque hay que considerar los efectos expansivos del tipo de cambio real en la IS. El caso de la devaluación recesiva es mucho más confuso, porque la curva de demanda agregada tendría una pendiente positiva.

19 Utilizamos este plano del tipo de cambio y la producción, y no el habitual, de la tasa de interés y la producción, porque la tasa de interés es exógena en este modelo, y es preferible que los gráficos contengan variables endógenas como el tipo de cambio. 
Figura 5

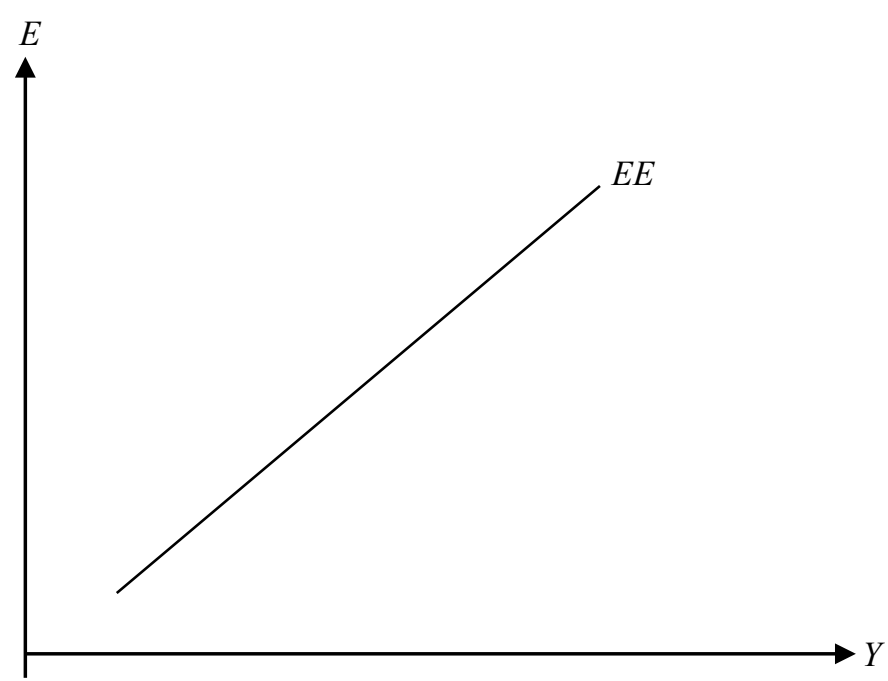

\section{b. La tasa de interés administrada y el mercado de dinero}

En este modelo, el instrumento de la política monetaria es la tasa de interés de corto plazo, la cual es administrada por el banco central ${ }^{20}$.

$$
r=r_{0}
$$

En el mercado monetario, en equilibrio, la oferta monetaria real , esto es, la oferta monetaria nominal $\left(M^{s}\right)$ deflactada por el nivel de precios $(P), M^{s}-P$, debe ser igual a la demanda monetaria real . La oferta monetaria nominal ${ }^{21}$ se origina en las reservas internacionales $\left(B^{* b c r}\right)$ y el stock de bonos domésticos en poder del banco central, denominado también crédito interno $\left(B^{b}\right)$. La demanda monetaria real es una función directa de la producción y una función inversa de la tasa de interés. En equilibrio, $M^{s}-P=B^{* b c r}+B^{b}-P=b_{0} Y-b_{1} r$

La fijación de la tasa de interés modifica el mecanismo de ajuste en el mercado monetario. Tradicionalmente, en un régimen con tipo de cambio flotante, la oferta monetaria nominal es exógena y la tasa de interés es la variable de ajuste para mantener el equilibrio en el mercado de dinero. La tasa de interés es exógena, la oferta monetaria es endógena y la variable de ajuste para mantener el equilibrio en el mercado monetario es el stock de bonos en moneda nacional (el crédito interno). El banco central realiza operaciones de mercado abierto, comprando o vendiendo esos bonos, para hacer que la tasa de interés se mantenga fija. Eso es lo que se representa con la ecuación (16).

${ }^{20}$ En un esquema de metas de inflación, la tasa de interés se comporta de acuerdo a alguna variedad de Regla de Taylor, como en Mendoza (2015). En este artículo, la tasa de interés es exógena.

${ }_{21}$ En rigor, la emisión primaria o dinero de alto poder, dado que en este modelo no hay bancos. 


$$
B^{b}=-B^{* b c r}+P+b_{0} Y-b_{1} r
$$

Esta ecuación serviría únicamente para determinar una variable endógena, el stock de bonos en moneda local en poder del banco central. Esta variable, sin embargo, es influenciada por el resto de variables endógenas del modelo, pero no ejerce ninguna influencia en ellas. Es decir, el modelo es recursivo: determinados los valores de la producción, el tipo de cambio y las reservas internacionales, puede determinarse el stock de bonos en moneda local; pero no hace falta conocer el stock de bonos para determinar las otras variables endógenas. Por eso, mantenemos aislado este mercado y no lo consideramos en el análisis de equilibrio general.

\section{c. El equilibrio externo}

Las ecuaciones de determinación de las reservas internacionales y del tipo de cambio fueron halladas en la sección 1, y están representadas por las ecuaciones (7) y (8), respectivamente.

A la ecuación (8) la denominaremos la ecuación de equilibrio externo (EE), porque resulta de la combinación de la ecuación de balanza de pagos y la regla de intervención cambiaria. A lo largo de esta curva, la balanza de pagos está financiada, en concordancia con la regla de intervención del banco central. La representamos en la figura 6 , su pendiente es positiva y viene dada por,

$$
\left.\frac{d E}{d Y}\right|_{E E}=\frac{m(1-t)}{\mu}>0
$$

Figura 6. La EE

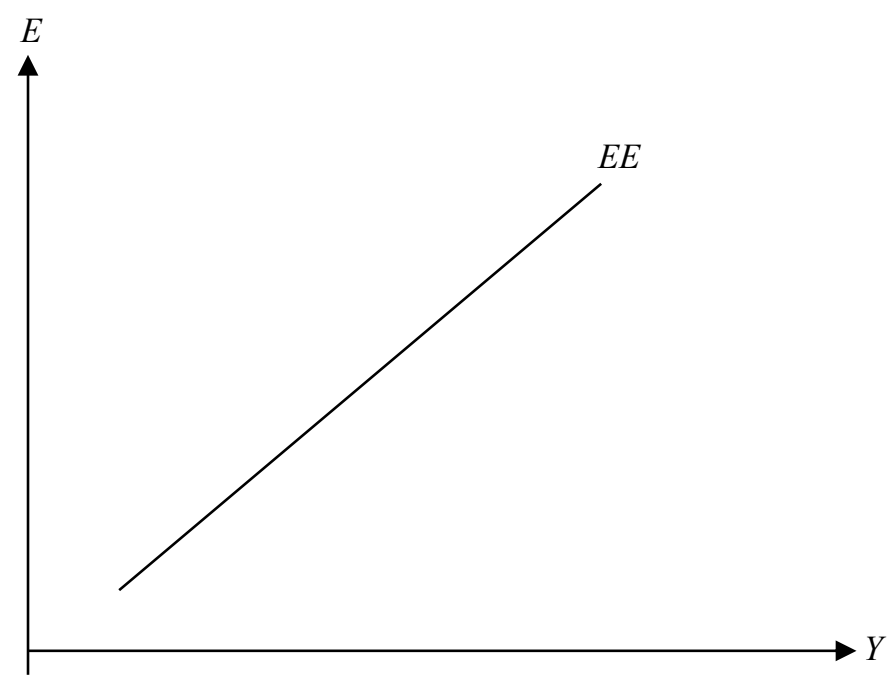




\section{d. El equilibrio general}

El equilibrio general se alcanza cuando hay equilibrio en el mercado de bienes (IS) y en el sector externo (EE), el que contiene a la balanza de pagos y la regla de intervención del banco central. En términos gráficos, la IS y la EE determinan la producción y el tipo de cambio. Conocido el tipo de cambio, el stock de reservas internacionales se determina en la RI, tal como se observa en la figura 7.

Figura 7. El equilibrio general

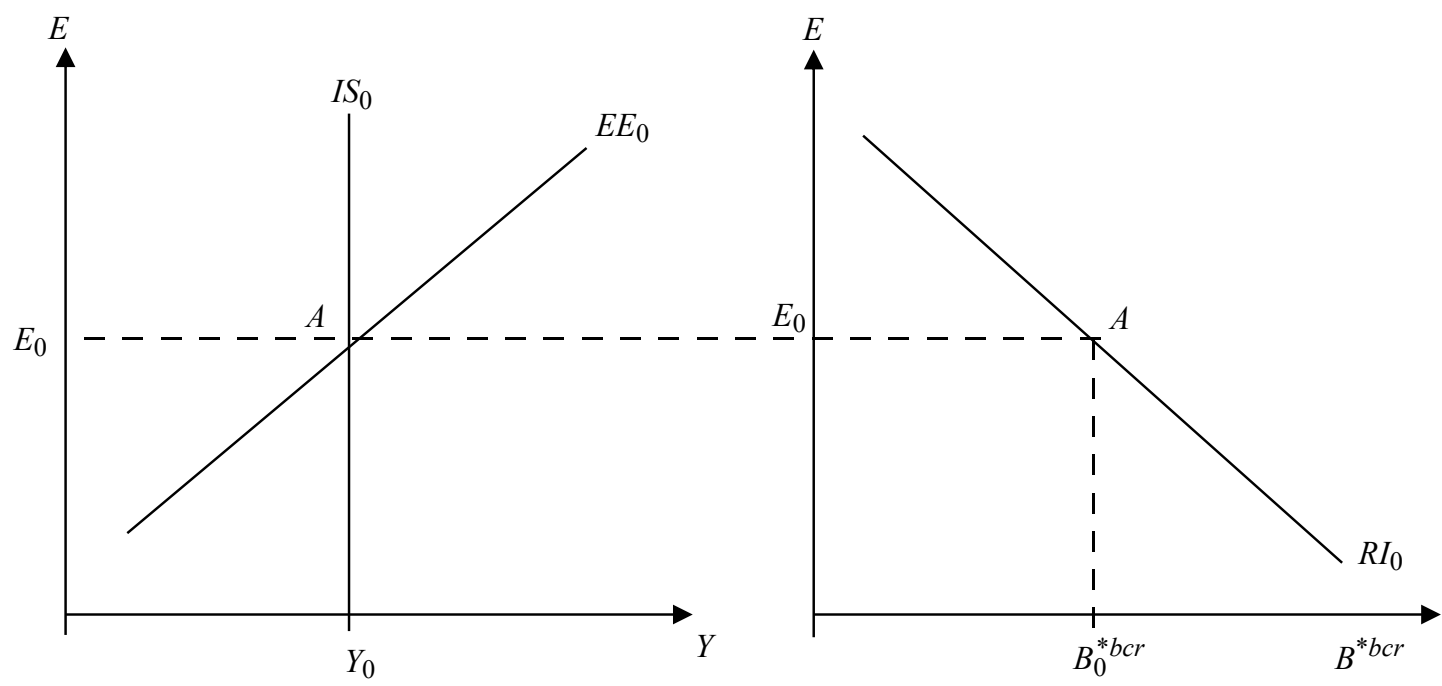

Para llegar al modelo en su forma reducida y hallar los valores de equilibrio de la producción, el tipo de cambio y las reservas internacionales, podemos combinar las ecuaciones (14), (8) y (5), del equilibrio en el mercado de bienes, el equilibrio externo y la regla de intervención, respectivamente. Hay otra manera más sencilla, dado que el modelo es recursivo, pues la producción es independiente del tipo de cambio. La producción de equilibrio se determina se determina solo en el mercado de bienes, al margen de las otras ecuaciones. Es lo que mostramos en la ecuación (17). El tipo de cambio de equilibrio, ecuación (18), lo obtenemos combinando la ecuación (14) con la ecuación (8). Por último, para obtener las reservas internacionales de equilibrio, reemplazamos el tipo de cambio de equilibrio que acabamos de obtener en la regla de intervención, ecuación (5). El modelo en su forma reducida viene entonces dado por,

$$
Y^{e q}=k\left[A_{0}+b^{X} P_{X}^{*}-\left(b+B^{g}\right) r-b^{*} r^{*}+a_{e}(E-P)\right]
$$




$$
\begin{aligned}
& E^{e q}=\frac{1}{\mu}\left[\beta_{0} E^{m}+a_{2} E^{e}-[1-c(1-t)] k\left[a_{0} Y^{*}+a_{1} P^{*}\right]+\left[\left(a_{1}+X_{0}\right)\right] P+\left[a_{2}[1-c(1-t)]+\right.\right. \\
& \left.m(1-t)\left[a_{2}-b^{*}+(E-P) a_{e}\right]\right] k r^{*}-\left[a_{2}[1-c(1-t)]+m(1-t)\left[a_{2}-\left(b+B^{g}\right)\right]\right] k r- \\
& \left.\left[X_{0}[1-c(1-t)]+m(1-t)\left(X_{0}-b^{X}\right)\right] k P_{X}^{*}+k m(1-t)\left[C_{0}+I_{0}+(t+\alpha) \bar{Y}+t \overline{P_{X}^{*}} X_{0}\right]\right] \\
& B^{* * b c r e q}=B_{t-1}^{* b c r}+\beta_{0}\left[\frac{\mu-\beta_{0}}{\mu}\right] E^{m}-\frac{\beta_{0}}{\mu}\left[a_{2} E^{e}-[1-c(1-t)] k\left[a_{0} Y^{*}+a_{1} P^{*}\right]+\left[\left(a_{1}+X_{0}\right)\right]\right. \\
& P+\left[a_{2}[1-c(1-t)]+m(1-t)\left[a_{2}-b^{*}+(E-P) a_{e}\right]\right] k r^{*}-\left[a_{2}[1-c(1-t)]+m(1-t)\right. \\
& \left.\left[a_{2}-\left(b+B^{g}\right)\right]\right] k r-\left[X_{0}[1-c(1-t)]+m(1-t)\left(X_{0}-b^{X}\right] k P_{X}^{*}+k m(1-t)\left[C_{0}+I_{0}+\right.\right. \\
& \left.\left.(t+\alpha) \bar{Y}+t \overline{P_{X}^{*}} X_{0}\right]\right]
\end{aligned}
$$

La ecuación (17), que muestra la independencia del nivel de actividad económica respecto al tipo de cambio real, es también la recta de demanda agregada (DA) de esta economía. Esta recta de DA es vertical porque al elevarse el nivel de precios, cae el tipo de cambio real. El menor tipo de cambio real tiene un efecto nulo sobre la demanda y por tanto sobre la producción industrial. La DA vertical se representa en la figura 8 .

Figura 8. La demanda agregada

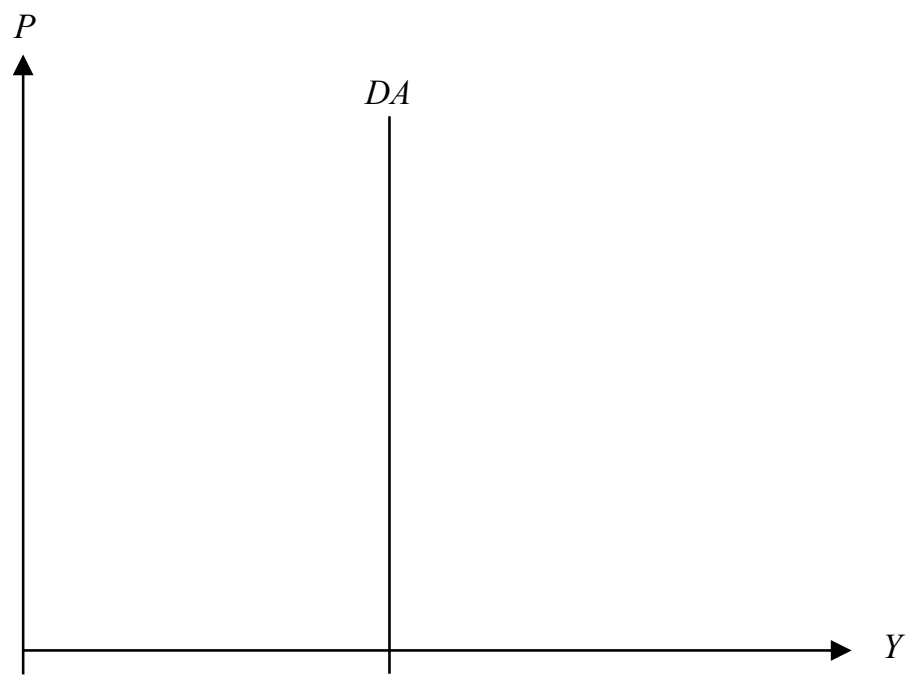




\section{LA OFERTA AGREGADA}

En este modelo de corto plazo, se asume que los precios están dados. No es de interés de este modelo el explicar sus determinantes ${ }^{22}$. La ecuación (20) es la de oferta agregada y se la muestra en la figura 9.

$$
P=P_{0}
$$

Figura 9. La oferta agregada

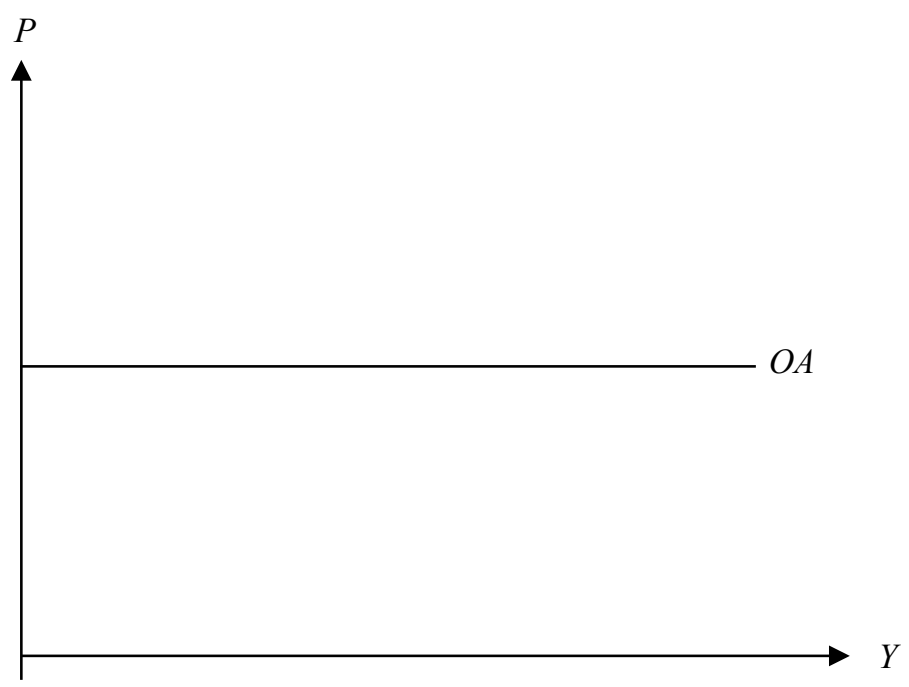

La figura 10 es la representación del modelo en su conjunto, con la determinación de sus 3 variables endógenas. En la parte inferior están la demanda y la oferta agregada, ecuaciones (17) y (20), respectivamente, las cuales determinan la producción de equilibrio. Dada la producción, en la parte superior izquierda se determinan el tipo de cambio, combinando la IS, el equilibrio en el mercado de bienes, con la EE, el equilibrio externo. Conocido el tipo de cambio, en la parte superior derecha, a través de la RI, la regla de intervención en el mercado cambiario, se halla el stock de reservas internacionales de equilibrio.

22 Cuando el nivel de precios depende de la brecha del PBI y el tipo de cambio, como en Dancourt y Mendoza (2016), el análisis se complica enormemente, especialmente porque hay que considerar el tipo de cambio, que es una variable endógena, como un argumento de la curva de oferta agregada. Esa opción ensombrecería lo que se quiere destacar aquí: cómo funciona la macroeconomía bajo un régimen de flotación sucia. 
Figura 10. El equilibrio general, la demanda y la oferta agregada
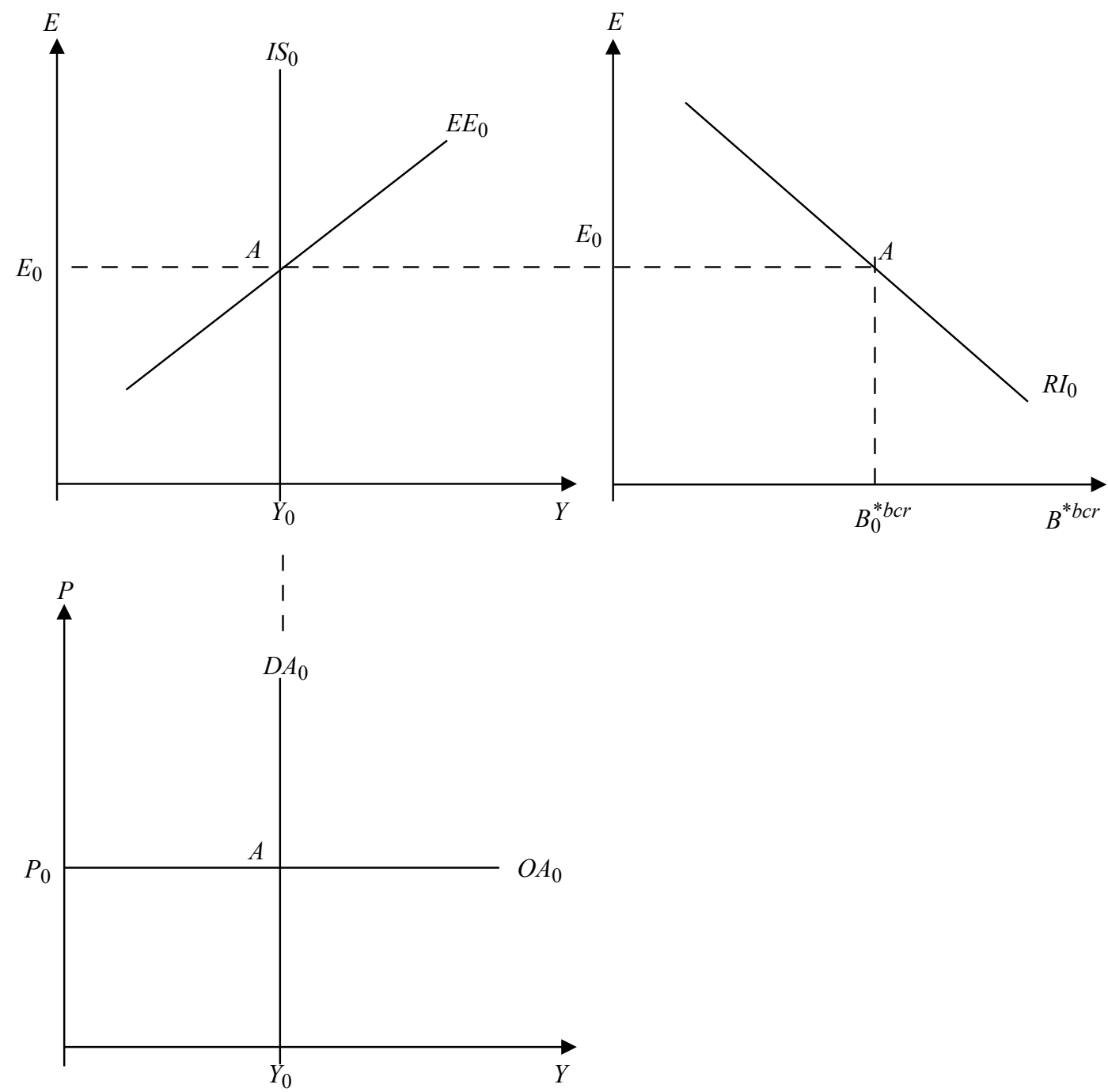

Las variables endógenas de este modelo son la producción, el tipo de cambio nominal y el stock de reservas internacionales ${ }^{23}$. Los instrumentos de la política monetaria son la tasa de interés de corto plazo y el tipo de cambio meta. Los instrumentos de la política fiscal son la tasa impositiva y el límite de déficit fiscal. Las variables del contexto internacional son el PBI mundial, la tasa de interés internacional, el precio mundial de los productos industriales y de las exportaciones de materias primas.

23 El modelo también determina el stock de bonos en moneda local. 
Hay que precisar que cuando se fija la tasa de interés de corto plazo, la intervención en el mercado cambiario tiene que ser necesariamente esterilizada. Es decir, la intervención en el mercado cambiario, que altera el volumen de reservas internacionales y en consecuencia la oferta monetaria nominal, tiene que ser complementada con una intervención en el mercado de bonos, de tal manera que $d B^{*} b c r=-d B^{b}$, para que la oferta monetaria nominal no se altere. De otra manera, se afectaría a la tasa de interés local.

\section{CHOQUE EXTERNO ADVERSO}

En esta sección vamos a evaluar los efectos sobre la inversión privada, la producción, el tipo de cambio y las reservas internacionales de un choque externo adverso, consistente en la reducción del precio internacional de las materias primas.

\section{CAÍdA DEL PRECIO INTERNACIONAL DE LAS MATERIAS PRIMAS}

La caída en el precio internacional de las exportaciones de materias primas, por un lado, genera una disminución en la inversión privada, pues esta depende del precio real de las exportaciones de materias primas. La menor inversión hace caer la demanda y en consecuencia la producción industrial.

El menor precio internacional de las materias primas, por otro lado, deteriora la balanza de pagos, provocando el alza del tipo de cambio nominal. Pero la menor producción industrial, al reducir las importaciones, alivia las presiones sobre el precio de la moneda extranjera, haciendo caer el tipo de cambio nominal. Asumimos que este efecto tiene menor fuerza sobre el tipo de cambio en comparación con el efecto directo del menor precio de las exportaciones primarias, con lo que el tipo de cambio nominal se eleva.

El mayor tipo de cambio nominal conduce, por un lado, al alza del tipo de cambio real lo que, en las condiciones descritas en este modelo, no afecta a la producción industrial. El mayor tipo de cambio nominal también induce al banco central que rema contra la corriente a vender dólares, lo que hace caer su volumen de reservas internacionales y amortigua el alza del tipo de cambio.

En resumen, un descenso del precio internacional de las materias primas hace caer la inversión privada, recesa la economía, eleva el tipo de cambio nominal y reduce el stock de reservas internacionales del banco central.

Los efectos de la caída del precio internacional de las materias primas se observan en la figura 11. En el panel inferior, el de la oferta y la demanda agregada, el choque externo adverso desplaza la demanda agregada hacia la izquierda.

En el panel superior izquierdo, tanto la IS como la EE se desplazan hacia la izquierda, por efecto del descenso del precio internacional de las materias primas. El desplazamiento de la EE es mayor que el de la IS, pues estamos suponiendo que el efecto del 
precio de las materias primas sobre el sector externo es más fuerte que en el mercado de bienes, con lo que el tipo de cambio se eleva. Por último, el mayor tipo de cambio, dada la RI, induce al banco central a reducir su tenencia de reservas internacionales.

Figura 11. Caída del precio internacional de las materias primas

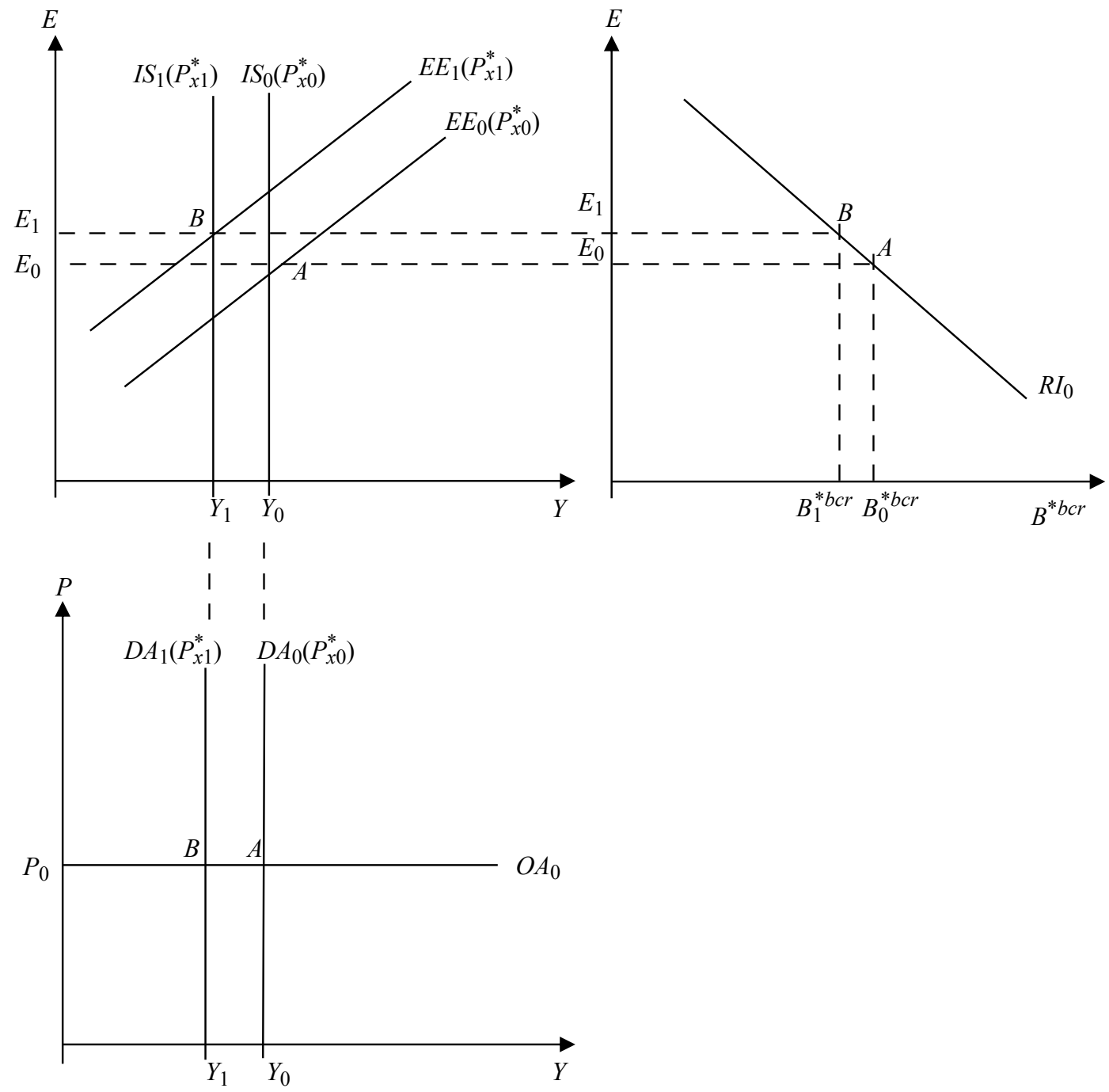

Los resultados matemáticos los obtenemos a partir de las ecuaciones en su forma reducida (18)-(20). Estos resultados confirman nuestros hallazgos: caída de la producción y de las reservas internacionales, y alza del tipo de cambio nominal.

$$
d Y=k b^{X} d P_{x}^{*}<0
$$




$$
\begin{aligned}
& d E=-\frac{k}{\mu}\left\{X_{0}[1-c(1-t)]+m(1-t)\left(X_{0}-b^{X}\right)\right\} d P_{X}^{*}>0^{24} \\
& d B^{* b c r}=\frac{\beta_{0} k}{\mu}\left\{X_{0}[1-c(1-t)]+m(1-t)\left(X_{0}-b^{X}\right)\right\} d P_{X}^{*}<0
\end{aligned}
$$

Hay que advertir, sin embargo, que estos resultados pueden variar conforme vayamos elevando la complejidad de este modelo. Para considerar el esquema de metas de inflación del BCRP habrá que incorporar necesariamente una curva de oferta agregada, en la que el nivel de precios depende a de las expectativas, la brecha del PBI y del tipo de cambio, y una regla de política monetaria en el que la tasa de interés responda a la brecha entre el precio meta y el precio observado, como en Mendoza (2015). Para modelar mejor la regla de intervención del banco central, entre otras tareas, habría que endogenizar el tipo de cambio meta. Por último, para incorporar la dinámica en el modelo se tendría que endogenizar las expectativas sobre el tipo de cambio y el nivel de precios. En el contexto de un modelo dinámico tendríamos que incorporar, además, los conceptos de equilibrio de corto plazo y de equilibrio estacionario

En ese escenario, mucho más complejo, un descenso del precio de las materias primas tendría un impacto incierto sobre el nivel de precios pues, por un lado, la recesión, que hace caer la brecha del PBI, haría caer el nivel de precios, pero el alza del tipo de cambio tendería a elevarlo.

Por otro lado, la caída en el precio de las exportaciones haría elevar el tipo de cambio meta, con lo cual, en el corto plazo, la venta de dólares del banco tendría que ser mucho más fuerte que en nuestro modelo base

Así mismo, si se incorporase la dinámica, en su versión de tiempo discreto, el descenso del precio de las exportaciones tendría efectos en la economía a lo largo del tiempo, hasta que alcance su nuevo nivel de equilibrio estacionario.

\section{CONCLUSIONES}

Se ha presentado un modelo macroeconómico construido para el estudio de una economía pequeña, abierta, exportadora de materias primas, con movilidad imperfecta de capitales, con un banco central que fija la tasa de interés interbancaria y mantiene un régimen de flotación sucia, y con una política fiscal donde existe un límite de déficit estructural. Es el caso del Perú.

El modelo ha sido utilizado para simular los efectos de un descenso del precio internacional de las materias primas de exportación sobre las variables endógenas del modelo.

\footnotetext{
${ }^{24}$ Como puede verse aquí, para que se alcance este resultado basta suponer que el impacto directo del precio de las materias primas sobre la balanza de pagos y, en consecuencia, sobre el tipo de cambio, $X_{0}$, sea mayor que el efecto del precio de las materias primas sobre la inversión privada $\left(b^{x}\right)$.
} 
Las predicciones del modelo son consistentes con la regla de intervención del BCRP y los principales hechos estilizados de la economía peruana desde el inicio del descenso del precio internacional de las materias primas a fines de 2011: caída drástica de la inversión, descenso del crecimiento del PBI, alza del tipo de cambio y reducción de las reservas internacionales. Los precios de las materias primas parecen gobernar el comportamiento de las principales variables de la macroeconomía peruana.

Hay que advertir, sin embargo, que en aras de la sencillez se han omitido en el modelo elementos que pueden complicar la sencilla versión apropiada para el desarrollo de ejercicios de estática comparativa presentado aquí.

\section{REFERENCIAS}

Adler, Gustavo, Noemie Lisack y Rui Mano (2015). Unveiling the Effects of Foreign Exchange Intervention: A Panel Approach. IMF Working Paper $\mathrm{N}^{\circ}$ 130. Washington, DC: International Monetary Fund.

Ball, Laurence (2012). Money, Banking, and Financial Markets, Second Edition, Worth Publishers. Blanchard, Olivier, Giovani Dell'Ariccia y Paolo Mauro (2010). Rethinking Macroeconomic Policy. IMF Staff Position Note.

Dancourt, Oscar (2013). Reglas de politica monetaria y choques externos en una economía semidolarizada. Economía, XXXVI(72), 91-116.

Dancourt Oscar y Waldo Mendoza (2016). Intervención cambiaria y política monetaria en el Perú. Documento de trabajo $\mathrm{N}^{\circ}$ 422, Departamento de Economía de la PUCP, Lima.

Díaz Alejandro, Carlos (1966). Exchange-Rate Devaluation in a Semi-Industrialized Country. The Experience of Argentina, 1955-1961. Massachusetts: The MIT Press.

Fondo Monetario Internacional (FMI) (2014). Resisting the Pressures from Capital Flows: Are Foreign Exchange Interventions Effective? Selected Issues Paper, IMF Country Report $\mathrm{N}^{\circ} 22$.

Fondo Monetario Internacional (FMI) (2015). World Economic Outlook, Adjusting to Lower Commodity Prices, octubre, Washington, DC.

Galindo, Arturo, Alejandro Izquierdo y José Manuel Montero (2007). Real Exchange rate, dollarization and industrial employment in Latin America. Emerging Markets Review, 8(4), 284-298.

Han, Fei (2014). Measuring External Risks for Peru: Insights from a Macroeconomic Model for a Small Open and Partially Dollarized Economy. International Monetary Fund Working Paper $\mathrm{N}^{\circ} 161$. Washington, DC: International Monetary Fund.

Krugman, Paul y Lance Taylor (1978). Contractionary effects of devaluation. Journal of International Economics, 8(3), 451-456.

Magud, Nicolás y Sebastián Sosa (2015). Investing in emerging markets. We Are not in Kansas Anymore...Or Are we? IMF Working Paper $\mathrm{N}^{\circ}$ 77. Washington, DC: International Monetary Fund

Mendoza, Waldo (2015). Fiscal rules, monetary rules and external shocks in a primary-export economy: a model for Latin America and the Caribbean, Documento de trabajo $\mathrm{N}^{\circ} 406$, Departamento de Economía de la PUCP. 
Ostry Jonathan, Atish R. Ghosh y Marcos Chamon (2012). Two Targets, Two Instruments: Monetary Policy and Exchange Rate Policies in Emerging Markets Economies. IMF Staff Discussion Note 12/01. Washington, DC: International Monetary Fund.

Ross, K. y M. Tashu (2015). Investment Dynamics in Peru. En A. Santos y A. Werner, Peru. Staying the Course of Economic Success. Washington, DC: International Monetary Fund.

Rossini, Renzo, Zenón Quispe y Donita Rodríguez (2011). Capital Flows, Monetary Policy and Forex Intervention in Peru. Documento de trabajo No 8. Lima: Banco Central de Reserva del Perú. 